\title{
Evaluation of pan coefficient equations in a semi-arid Mediterranean environment using the ASCE-standardized Penman-Monteith method
}

\author{
Vassilis G. Aschonitis, Vassilis Z. Antonopoulos`, Dimitris M. Papamichail \\ Department of Hydraulics, Soil Science and Agricultural Engineering, School of Agriculture, Aristotle University of Thessaloniki, \\ Thessaloniki, Greece; ${ }^{*}$ Corresponding Author: vasanton@agro.auth.gr
}

Received 10 September 2011; revised 22 November 2011; accepted 6 December 2011

\begin{abstract}
Reference crop evapotranspiration $\left(E T_{o}\right)$ is essential for irrigation, water resources management and environmental assessment. The indirect estimation of $E T_{o}$ is based a) on energy budget approach using meteorological data and b) pan evaporation measurements $\left(E_{\text {pan }}\right)$ multiplied by pan coefficients $\left(k_{p}\right)$ adapted to the surrounding environmental conditions. Significant interest is shown for the $k_{p}$ equations, which have to be tested before their use. The purpose of this study is to evaluate six different $k_{p}$ equations, such as those of Cuenca, Allen and Puitt, Snyder, Pereira et al., Orang, Raghuwanshi and Wallender for the summer growing season (April to October) of Thessaloniki plain in Greece, which is characterized by a semi-arid Mediterranean environment. The evaluation of the $k_{p}$ equations is performed by two years $E_{p a n}$ measurements, using as reference the daily $E T_{o}$ values estimated by the ASCE-standardized Penman-Monteith equation (ASCE-PM) in hourly time step. The results of this study showed that Cuenca's equation provided more accurate daily estimations. Additional analysis is performed in other methods such as those of FAO-56 and Hargreaves based on the calculation time step (hourly or daily) and their correspondence to the ASCE-PM.
\end{abstract}

Keywords: Pan Evaporation; Reference Evapotranspiration; ASCE-Standardized Penman-Monteith

\section{INTRODUCTION}

The reference crop evapotranspiration $\left(E T_{o}\right)$ constitutes the major factor for the accurate estimation of the crop water requirements, which are essential in irrigation planning, scheduling, hydrologic balance studies and watershed hydrology. Many methods have been proposed for the estimation of $E T_{o}$, based on the energy budget approach, such as the corrected FAO-24 Blaney-Criddle method [1], the Priestley-Taylor method [2], the corrected FAO-24 Penman method [3], the Shuttleworth and Wallace method [4], the Hargreaves method [5], the FAO-56 Penman-Monteith method [6] and the ASCEstandardized Penman-Monteith method [7]. Numerous of empirical linear and non-linear equations have also been developed but with restricted validity at regional scale. The FAO-56 Penman-Monteith constitutes the most popular methodology in agricultural studies and the ASCEstandardized Penman-Monteith method was recently presented as an improvement of this by the ASCE-EWRI Task Committee [7].

Significant efforts for the correct estimation of $E T_{o}$ under the Greek environmental-meteorological conditions have been carried out by several researchers, which they focused on comparisons and sensitivity analysis between the aforementioned methods, their parameters and their calculation time step [8-11]. Additional studies have been performed for the development of new methodologies for the estimation of $E T_{o}$ using empirical equations such as the "Copais model" [12] or equations based on Penman formula with reduced parameters [13].

A different approach for $E T_{o}$ estimation is the use of pan evaporation measurements $\left(E_{\text {pan }}\right)$ and pan coefficients $\left(k_{p}\right)$. The $k_{p}$ is obtained as a constant value adjusted to specific environmental conditions [6] or as equations $[14,15]$. The use of $E_{p a n}$ measurements and $k_{p}$ coefficients has the advantage of the low cost equipment, while it has the disadvantage of the $k_{p}$ calibration and the frequent visits for the preservation of water level and clarity versus the agro-meteorological stations.

The objective of this study is to compare and evaluate different equations for the pan coefficient $k_{p}$ using ClassA pan evaporimeter measurements for the estimation of 
$E T_{o}$ during the summer crop growing season (April to October). Measurements were obtained in Thessaloniki region, which is under a semi-arid Mediterranean environment and constitutes one of the major plains for agricultural production in Greece. Due to the lack of equipment for the direct measurement of the reference crop evapotranspiration (e.g. weighted lysimeters), the method of ASCE-standardized Penman-Monteith method (ASCE-PM) calculated in hourly time step, was selected to be used as reference for the comparisons between the different $k_{p}$ equations. The comparison between the ASCE-PM and other popular methods such as those of FAO-56 Penman-Monteith and Hargreaves was also performed.

\section{METHODOLOGY AND DATA}

\subsection{Estimation of the Reference Crop Evapotranspiration}

\subsubsection{The Methods of ASCE and FAO-56 Penman-Monteith}

ASCE-EWRI (2005) have proposed two reference crops, a short crop similar to a clipped-grass $(0.12 \mathrm{~m}$ height) and a tall crop similar to a full cover alfa-alfa (0.5 m height) [7]. Considering the two reference crops, the ASCE-EWRI Task Committee revised and improved the FAO-56 Penman-Monteith (FAO56-PM) equation, presenting the new ASCE Penman-Monteith (ASCE-PM) method. The equation of ASCE-PM using daily or hourly time step for the two different cases of reference crop is given by [7]:

$$
E T_{o}=\frac{0.408 \Delta\left(R_{n}-G\right)+\gamma\left(\frac{C_{n}}{(T+273.16)}\right) u_{2}\left(e_{s}-e_{a}\right)}{\Delta+\gamma\left(1+C_{d} u_{2}\right)}
$$

where $E T_{o}$ is the reference crop evapotranspiration for short (ETos) or tall (ETrs) reference crops $\left(\mathrm{mm} \cdot \mathrm{d}^{-1}\right.$ for daily time step or $\mathrm{mm} \cdot \mathrm{h}^{-1}$ for hourly time step), $R_{n}$ is the net radiation at the crop surface $\left(\mathrm{MJ} \cdot \mathrm{m}^{-2} \cdot \mathrm{d}^{-1}\right.$ for daily time step or $\mathrm{MJ} \cdot \mathrm{m}^{-2} \cdot \mathrm{h}^{-1}$ for hourly time step), $u_{2}$ is the mean daily or hourly wind speed at $2 \mathrm{~m}$ height $\left(\mathrm{m} \cdot \mathrm{s}^{-1}\right), T$ is the mean daily or hourly air temperature at $2 \mathrm{~m}$ height $\left({ }^{\circ} \mathrm{C}\right), G$ is the soil heat flux density at the soil surface $\left(\mathrm{MJ} \cdot \mathrm{m}^{-2} \cdot \mathrm{d}^{-1}\right.$ for daily time step or $\mathrm{MJ} \cdot \mathrm{m}^{-2} \cdot \mathrm{h}^{-1}$ for hourly time step), $e_{s}$ is the daily or hourly saturation vapor pressure $(\mathrm{kPa}), e_{a}$ is the daily or hourly mean actual vapor pressure $(\mathrm{kPa}), \Delta$ is the slope of the saturation vapor pressure-temperature curve $\left(\mathrm{kPa} \cdot{ }^{\circ} \mathrm{C}^{-1}\right), \gamma$ is the psychrometric constant $\left(\mathrm{kPa} \cdot{ }^{\circ} \mathrm{C}^{-1}\right), C_{n}$ and $C_{d}$ are constants, which vary according to the time step, the reference crop type (bulk surface resistance, and aerodynamic roughness of the surface) and daytime/nighttime ratio.

According to the time step and the type of the reference crop, the values of $C_{n}, C_{d}$ and $G$ are modified and the Eq.1 is referred to different methods (Table 1):

- Two cases for daily time step a) the ASCE-PMos(d) which is the same with the FAO56-PM(d) for short reference crop and b) the ASCE-PMrs(d) for tall reference crop.

- Three cases for hourly time step calculations a) the $\operatorname{ASCE}-\mathrm{PMos}(\mathrm{h})$ for short reference crop, b) the ASCE-PMrs(h) for tall reference crop and c) the FAO56-PM(h) for short reference crop.

The calculation of saturation vapour pressure $e_{s}$, actual vapour pressure $e_{a}$, net longwave radiation $R_{n l}$ and soil heat flux $G$ is carried out by different equations accordingly to the time step [6,7]. The selected equations of $e_{s}$, $e_{a}$ and $R_{n l}$, that concern the daily calculations, were chosen after comparisons with the respective ones that concern the hourly time step calculations (Table 1 and Appendix).

\subsubsection{Hargreaves Method}

The Hargreaves equation $H G(d)$ [5] is calculated in a daily step and is given by:

$$
E T_{o}=a_{\mathrm{h}}\left(T_{\text {mean }}+b_{\mathrm{h}}\right)\left(T_{\text {max }}-T_{\text {min }}\right)^{c_{\mathrm{h}}} R_{a}
$$

where $E T_{o}$ is the reference crop evapotranspiration $\left(\mathrm{mm} \cdot \mathrm{d}^{-1}\right), T_{\text {mean }}$ is the mean daily air temperature $\left({ }^{\circ} \mathrm{C}\right)$,

\begin{tabular}{|c|c|c|c|c|c|}
\hline & Method & Calculation step & Coefficients & Heat flux $-G$ & $e_{s}, e_{a}, R_{n 1}$ \\
\hline 1 & ASCE-PMos(h) & hour & $\begin{array}{l}C_{n}=37, C_{d}=0.24 \text { for } R_{n}>0 \\
C_{n}=37, C_{d}=0.96 \text { for } R_{n}<0\end{array}$ & $\begin{array}{l}G=0.1 R_{n} \text { for } R_{n}>0 \\
G=0.5 R_{n} \text { for } R_{n}<0\end{array}$ & $(\mathrm{~A} 1, \mathrm{~A} 2, \mathrm{~A} 3)$ \\
\hline 2 & ASCE-PMrs(h) & hour & $\begin{array}{c}C_{n}=66, C_{d}=0.25 \text { for } R_{n}>0 \\
C_{n}=66, C_{d}=1.7 \text { for } R_{n}<0\end{array}$ & $\begin{array}{c}G=0.04 R_{n} \text { for } R_{n}>0 \\
G=0.2 R_{n} \text { for } R_{n}<0\end{array}$ & $(\mathrm{~A} 1, \mathrm{~A} 2, \mathrm{~A} 3)$ \\
\hline 3 & FAO56-PM(h) & hour & $\begin{array}{l}C_{n}=37, C_{d}=0.34 \text { for } R_{n}>0 \\
C_{n}=37, C_{d}=0.34 \text { for } R_{n}<0\end{array}$ & $\begin{array}{l}G=0.1 R_{n} \text { for } R_{n}>0 \\
G=0.5 R_{n} \text { for } R_{n}<0\end{array}$ & $(\mathrm{~A} 1, \mathrm{~A} 2, \mathrm{~A} 3)$ \\
\hline 4 & FAO56-PM(d) and ASCE-PMos(d) & day & $C_{n}=900, C_{d}=0.34$ & $G \approx 0$ & $(\mathrm{~A} 4, \mathrm{~A} 5, \mathrm{~A} 6)$ \\
\hline 5 & $\operatorname{ASCE}-\mathrm{PMrs}(\mathrm{d})$ & day & $C_{n}=1600, C_{d}=0.38$ & $G \approx 0$ & $(\mathrm{~A} 4, \mathrm{~A} 5, \mathrm{~A} 6)$ \\
\hline 6 & $\mathrm{HG}(\mathrm{d})$ & day & $a_{h}=0.0023, b_{h}=17.8, c_{h}=0.5$ & - & - \\
\hline
\end{tabular}

Table 1. Characteristics of the selected reference crop evapotranspiration methods. 
$T_{\min }$ is the minimum daily air temperature $\left({ }^{\circ} \mathrm{C}\right), T_{\max }$ is the maximum daily air temperature $\left({ }^{\circ} \mathrm{C}\right), R_{a}$ is the total extraterrestrial solar radiation $\left(\mathrm{mm} \cdot \mathrm{d}^{-1}\right), \alpha_{h}, b_{h}$ and $c_{h}$ are Hargreaves' equation coefficients (Table 1).

\subsection{Epan and Pan Coefficient Equations}

One of the most popular methods for the indirect $E T_{o}$ estimation is through $E_{p a n}$ measurements and $k_{p}$ coefficients adjusted to the surrounding environment and conditions (e.g. relative humidity, wind speed and windward side distance of green crop or a dry fallow).

The relationship between $E T_{o}$ and $E_{p a n}$ is given by the following equation [6]:

$$
E T_{o}=k_{p} E_{p a n}
$$

where $E_{p a n}$ is the pan evaporation $\left(\mathrm{mm} \cdot \mathrm{d}^{-1}\right)$ and $k_{p}$ is the pan coefficient.

Based on literature review, the values of $k_{p}$ cover a range between 0.3 and 1.1 , and are proportional to relative humidity and inverse proportional to wind speed $[6,14,15]$. Significant efforts have been performed for the indirect estimation of $k_{p}$ by equations, that use meteorological data and the characteristics of the surrounding environment, such as those of Cuenca [16], Allen and Puitt [3], Snyder [17], Pereira et al. [18], Orang [19], Raghuwanshi and Wallender [20] for the case of Class-A pan evaporimeter. The above equations are used for the estimation of $E T_{o}$ for the short reference crop and are given, respectively, by:

$$
\begin{gathered}
k_{p}=0.475-2.4 \times 10^{-4} u_{2}+5.16 \times 10^{-3} R H \\
+1.18 \times 10^{-3} F-1.6 \times 10^{-5} R H^{2}-1.01 \times 10^{-6} F^{2} \\
-8 \times 10^{-9} R H^{2} u_{2}-1 \times 10^{-8} H^{2} F \\
k_{p}=0.108-0.000331 u_{2}+0.0422 \ln (F) \\
+0.1434 \ln (R H)-0.000631[\ln (F)]^{2} \ln (R H) \\
k_{p}=0.482-0.000376 u_{2}+0.024 \ln (F)+0.0045 R H \\
k_{p}=0.85(\Delta+\gamma) /\left[\Delta+\gamma\left(1+0.33 u_{2}\right)\right] \\
k_{p}=0.51206-0.000321 u_{2} \\
\quad+0.031886 \ln (F)+0.002889 R H \\
k_{p}=0.5944+0.0242 X_{1}-0.0583 X_{2}-0.1333 X_{3} \\
\quad-0.2083 X_{4}+0.0812 X_{5}+0.1344 X_{6}
\end{gathered}
$$

where $R H$ is the mean daily relative humidity $(\%), u_{2}$ is the mean daily wind speed at $2 \mathrm{~m}$ above the soil surface (in $\mathrm{km} \cdot \mathrm{d}^{-1}$ for the Eqs.4, 5, 6, 8 and in $\mathrm{m} \cdot \mathrm{s}^{-1}$ for the Eq.7) and $F$ is the windward side distance of green crop or a dry fallow (m). For the Eq.9, $X_{1}=\ln (F), X_{2}, X_{3}$ and $X_{4}$ are wind speed categories of $175-425,425-700$, and
$>700 \mathrm{~km} \cdot \mathrm{d}^{-1}$, respectively, and are assigned values of one or zero depending upon their presence. A zero value for these variables represents a wind speed of $<175$ $\mathrm{km} \cdot \mathrm{d}^{-1}$. Similarly, $X_{5}$ and $X_{6}$ are relative humidity categories of $40 \%-70 \%$ and $\geq 70 \%$, respectively. Again the values of one or zero were assigned depending on their presence and a zero value for these variables represents a relative humidity of $\leq 40 \%$.

\subsection{Study Site and Measurements}

Hourly meteorological data of temperature, relative humidity, solar radiation, wind speed and precipitation obtained by the meteorological station of the Aristotle University of Thessaloniki farm (40 $\left.32^{\prime} 08^{\prime \prime} \mathrm{N}, 22^{\circ} 59^{\prime} 18^{\prime \prime} \mathrm{E}\right)$, covering the summer growing season (April to October) for three years (2008-2010) were used for the $E T_{o}$ estimations. The mean monthly values of the meteorological data for the period 2008-2010 are presented in Table 2.

Daily $E_{p a n}$ measurements were colected using Class-A pan evaporimeter for two years (2008-2009). The data describe adequately the meteorological conditions of the Thessaloniki plain, where the climate is considered as a semi-arid Mediterranean environment.

\section{RESULTS AND DISCUSSION}

\subsection{Estimation and Evaluation of $E T_{o}$ Methods}

The daily $E T_{o}$ for the summer growing season (April to October) was estimated using the methods presented in Table 1. The daily $E T_{o}$ values of ASCE-PM method, calculated for hourly time-step, were used as reference for the comparisons among the methods presented in Table 1. The mean daily values of $E T_{o}\left(\mathrm{~mm} \cdot \mathrm{d}^{-1}\right)$ for each method and the transition coefficients for each one in order to be converted in ASCE-PMos(h) are given in Table 3.

The comparisons among the methods for the short reference crop are given in Figures 1(a)-(c), while for the tall reference crop in Figure 1(d). The statistical tests of the coefficient of determination $\left(R^{2}\right)$, the root mean square error (RMSE) and the mean bias error (MBE) were used for the comparison analysis [12,21] and are given by:

$$
\begin{gathered}
R^{2}=\left[\frac{\sum_{i=1}^{N}\left(C_{i}-C_{m}\right)\left(O_{i}-O_{m}\right)}{\sqrt{\sum_{i-1}^{N}\left(C_{i}-C_{m}\right)^{2}} \cdot \sqrt{\sum_{i-1}^{N}\left(O_{i}-O_{m}\right)^{2}}}\right]^{2} \\
R M S E=\sqrt{\frac{1}{N} \sum_{i=1}^{N}\left(C_{i}-O_{i}\right)^{2}}
\end{gathered}
$$


Table 2. Mean monthly values of the meteorological parameters during the period of April-October for 2008-2010.

\begin{tabular}{cccccc}
\hline Month & $\begin{array}{c}\text { Mean monthly } \\
\text { temperature } \mathrm{T}\left({ }^{\circ} \mathrm{C}\right)\end{array}$ & $\begin{array}{c}\text { Mean monthly relative } \\
\text { humidity RH\% }\end{array}$ & $\begin{array}{c}\text { Mean monthly incident } \\
\text { solar radiation } R_{s}\left(\mathrm{w} \cdot \mathrm{m}^{-2}\right)\end{array}$ & $\begin{array}{c}\text { Mean monthly wind } \\
\text { speed } \mathrm{u}_{2}\left(\mathrm{~m} \cdot \mathrm{s}^{-1}\right)\end{array}$ & $\begin{array}{c}\text { Mean monthly } \\
\text { precipitation }(\mathrm{mm})\end{array}$ \\
\hline April & 14.5 & 71.8 & 202.9 & 1.6 & 42.5 \\
May & 19.9 & 63.3 & 268.0 & 1.7 & 31.8 \\
June & 24.3 & 61.3 & 285.4 & 1.5 & 47.3 \\
July & 27.1 & 54.2 & 304.4 & 1.6 & 20.4 \\
August & 27.5 & 55.9 & 260.6 & 1.3 & 26.7 \\
September & 21.7 & 63.4 & 181.3 & 1.3 & 35.3 \\
October & 16.4 & 73.8 & 127.3 & 1.2 & 63.4 \\
\hline
\end{tabular}

Table 3. Mean daily values of $E T_{o}\left(\mathrm{~mm} \cdot \mathrm{d}^{-1}\right)$ for each method and transition coefficients for each method using the daily $E T_{o}$ values of ASCE-PMos(h) as reference.

\begin{tabular}{|c|c|c|c|c|c|c|c|c|c|c|c|c|}
\hline \multirow{4}{*}{$\begin{array}{c}\text { Method } \\
\text { Month/unit } \\
\text { April }\end{array}$} & \multicolumn{8}{|c|}{ Short reference crop } & \multicolumn{4}{|c|}{ Tall reference crop } \\
\hline & \multicolumn{2}{|c|}{ ASCE-PMos(h) } & \multicolumn{2}{|c|}{ FAO56-PM(h) } & \multicolumn{2}{|c|}{$\begin{array}{l}\text { ASCE-PMos(d) } \\
\text { FAO56-PM(d) }\end{array}$} & \multicolumn{2}{|c|}{$\mathrm{HG}(\mathrm{d})$} & \multicolumn{2}{|c|}{ ASCE-PMrs(h) } & \multicolumn{2}{|c|}{ ASCE-PMrs(d) } \\
\hline & \multicolumn{2}{|c|}{$\left(\mathrm{mm} \cdot \mathrm{d}^{-1}\right)$} & \multicolumn{2}{|c|}{$\left(\mathrm{mm} \cdot \mathrm{d}^{-1}\right)$} & \multicolumn{2}{|c|}{$\left(\mathrm{mm} \cdot \mathrm{d}^{-1}\right)$} & \multicolumn{2}{|c|}{$\left(\mathrm{mm} \cdot \mathrm{d}^{-1}\right)$} & \multicolumn{2}{|c|}{$\left(\mathrm{mm} \cdot \mathrm{d}^{-1}\right)$} & \multicolumn{2}{|c|}{$\left(\mathrm{mm} \cdot \mathrm{d}^{-1}\right)$} \\
\hline & $3.13^{\dagger}$ & $(1.00)^{\ddagger}$ & 3.00 & $(1.043)$ & 2.87 & $(1.091)$ & 2.83 & $(1.106)$ & 3.70 & $(0.846)$ & 3.44 & $(0.910)$ \\
\hline May & 4.78 & $(1.00)$ & 4.60 & (1.039) & 4.49 & $(1.065)$ & 4.36 & $(1.096)$ & 5.73 & $(0.834)$ & 5.38 & $(0.888)$ \\
\hline June & 5.48 & $(1.00)$ & 5.31 & $(1.032)$ & 5.31 & $(1.032)$ & 5.18 & $(1.058)$ & 6.52 & $(0.840)$ & 6.30 & $(0.870)$ \\
\hline July & 6.22 & $(1.00)$ & 6.04 & $(1.030)$ & 6.10 & $(1.020)$ & 5.85 & $(1.063)$ & 7.55 & $(0.824)$ & 7.42 & $(0.838)$ \\
\hline August & 5.35 & $(1.00)$ & 5.22 & $(1.025)$ & 5.19 & $(1.031)$ & 5.07 & $(1.055)$ & 6.46 & $(0.828)$ & 6.29 & $(0.851)$ \\
\hline September & 3.38 & $(1.00)$ & 3.29 & $(1.027)$ & 3.21 & $(1.053)$ & 3.11 & $(1.087)$ & 4.13 & $(0.818)$ & 3.96 & $(0.854)$ \\
\hline October & 1.98 & $(1.00)$ & 1.92 & $(1.031)$ & 1.78 & $(1.112)$ & 1.88 & $(1.053)$ & 2.40 & $(0.825)$ & 2.23 & $(0.888)$ \\
\hline
\end{tabular}

$\dagger$ Mean daily values $\ddagger$ Transition coefficients calculated as ASCE-PMos(h)/other method.

$$
M B E=\frac{1}{N} \sum_{i=1}^{N}\left(C_{i}-O_{i}\right)
$$

where $O$ are the observed values (the reference values of ASCE-PM in hourly time step), $C$ are the computed values by the other methods and $O_{m}$ and $C_{m}$ are the mean observed and computed values, respectively.

The results showed a relative underestimation of the calculated $E T_{o}$ (relatively small values of RMSE and negative values of $\mathrm{MBE}$ ) for all the methods compared to the daily $E T_{o}$ values of ASCE-PM method in hourly time-step, for both cases of the reference crop. Considering the simplicity of the Hargreaves model, it was found a very good correspondence with the ASCEPMos(h), but it deflects for the days where the wind speed override the values of $1.5-2.0 \mathrm{~m} \cdot \mathrm{s}^{-1}$. In order to correct the results of each method using the ASCE-PM(h) as reference for the summer growing season, either the transition coefficients for each month or the regression equations from Figure 1 can be used. The $E T_{o}$ values of the ASCE-PM(h) for the tall reference crop were found about $10 \%$ - 20\% higher of those for short reference crop. The transition coefficients also allow the conversion from tall to short $E T_{o}$ values and the opposite.

\subsection{Evaluation of Pan Coefficients Equations}

The evaluation of $k_{p}$ selected equations (Eqs.4 to 9) was performed using as reference the ASCE-PMos(h) and the daily $E_{p a n}$ measurements of a Class-A pan evaporimeter, which was established at $F=0.25 \mathrm{~m}$ from active growing crop (Figures 2(a)-(f)). The mean monthly observed values of $k_{p}$ derived by the ratio ASCE$\operatorname{PMos}(\mathrm{h}) / E_{\text {pan }}$, for the total period of April to October, were 0.7 and 0.71 for 2008 and 2009, respectively. The mean monthly $k_{p}$ values for the 2 -years study period using the Eqs.3 up to 9 are given in Table 4. Using the ASCE-PMos(h) for the estimation of the daily $E T_{o}$ and the statistical criteria of $\mathrm{R}^{2}, \mathrm{RMSE}$ and MBE (Figure 2) from the comparison analysis between the different $k_{p}$ equations, resulted the following order in prediction ac- 


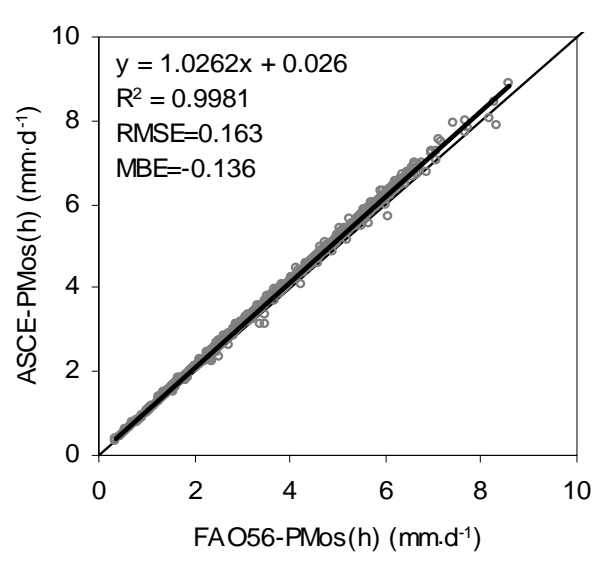

(a)

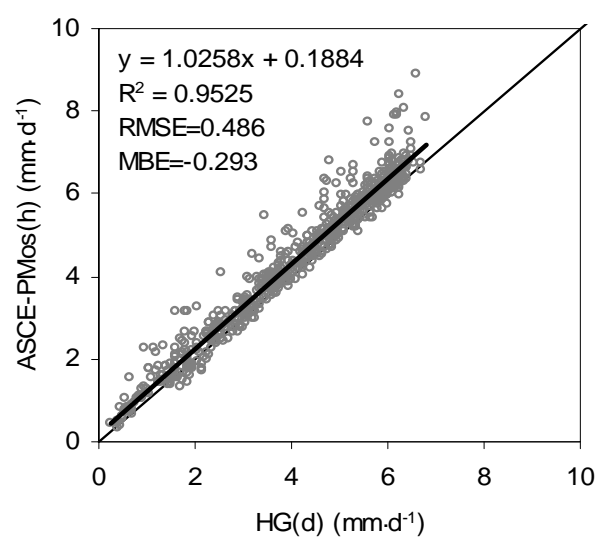

(c)

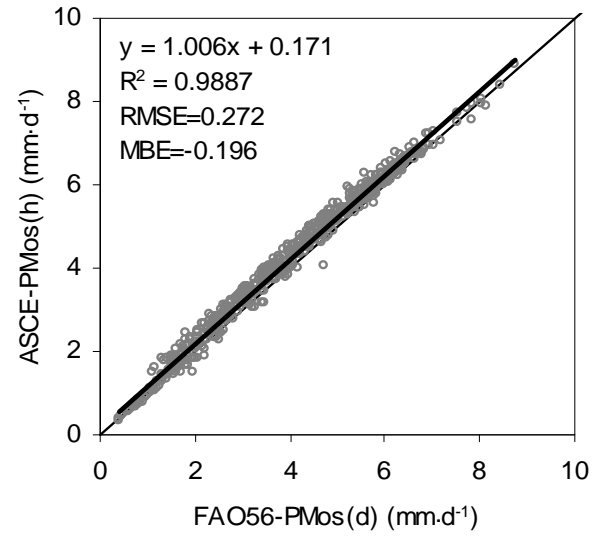

(b)

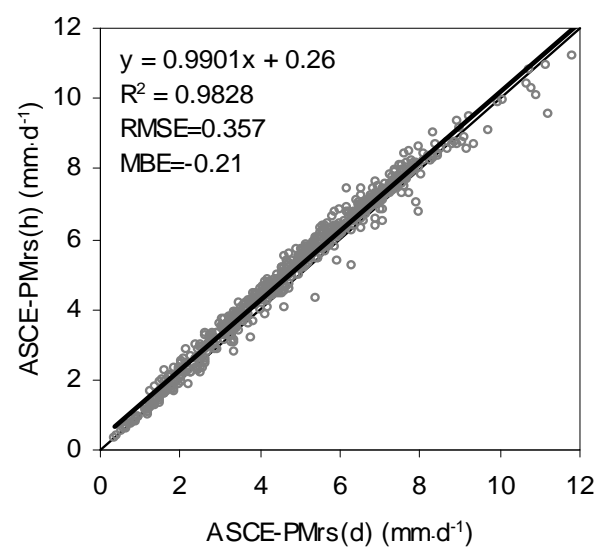

(d)

Figure 1. Comparison of the daily $E T_{o}$ estimated by the methods of ASCE-PMos(h) against (a) FAO56-PMos(h); (b) FAO56-PMos(d); (c) HG(d) for short reference crop and (d) by ASCEPMrs(d) for tall reference crop.

Table 4. Mean monthly values of the observed $k_{p}\left(E T_{o} / E_{p a n}\right)$ and mean monthly values using the different $k_{p}$ equations.

\begin{tabular}{cccccccc}
\hline Month & ${ }^{\dagger} E T_{o} / E_{\text {pan }}$ & Snyder & Pereira et al. & Orang & Allen \& Pruitt & Cuenca & Raghuwanshi \& Wallender \\
\hline April & 0.76 & 0.43 & 0.71 & 0.65 & 0.66 & 0.73 & 0.67 \\
May & 0.74 & 0.38 & 0.73 & 0.62 & 0.64 & 0.70 & 0.65 \\
June & 0.69 & 0.37 & 0.75 & 0.61 & 0.63 & 0.69 & 0.65 \\
July & 0.67 & 0.32 & 0.75 & 0.58 & 0.61 & 0.66 & 0.63 \\
August & 0.70 & 0.36 & 0.77 & 0.60 & 0.62 & 0.68 & 0.64 \\
September & 0.75 & 0.40 & 0.76 & 0.63 & 0.64 & 0.71 & 0.65 \\
October & 0.76 & 0.42 & 0.75 & 0.65 & 0.65 & 0.73 & 0.66 \\
Average & 0.71 & 0.38 & 0.75 & 0.61 & 0.63 & 0.69 & 0.65 \\
\hline
\end{tabular}

${ }^{\dagger} E T_{o}$ is calculated using ASCE-PMos(h) method.

curacy: Cuenca (Eq.4) > Raghuwanshi \& Wallender (Eq. 9) $>$ Allen \& Pruit (Eq.5) $>$ Pereira et al. (Eq.7) $>$ Orang (Eq.8) $>$ Snyder (Eq.6). The equation of Cuenca indicated the best adaptation to the ASCE-PMos(h) method compared to the other equations and adequate performance for the estimation of $E T_{o}$ under the climatologicalenvironmental conditions of the study area.

Taking into account the results of other similar studies 


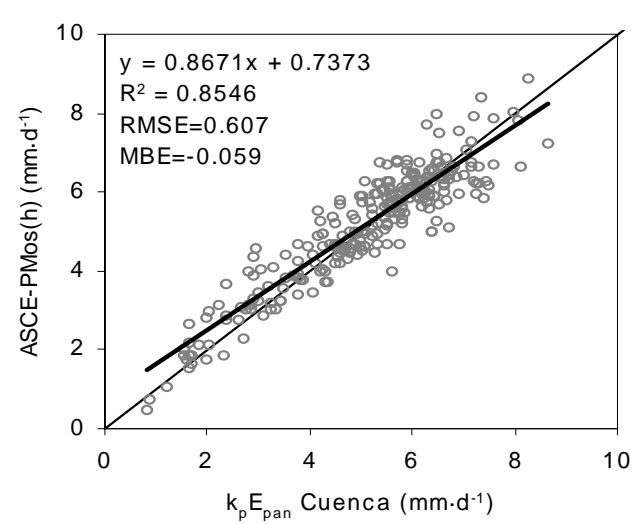

(a)

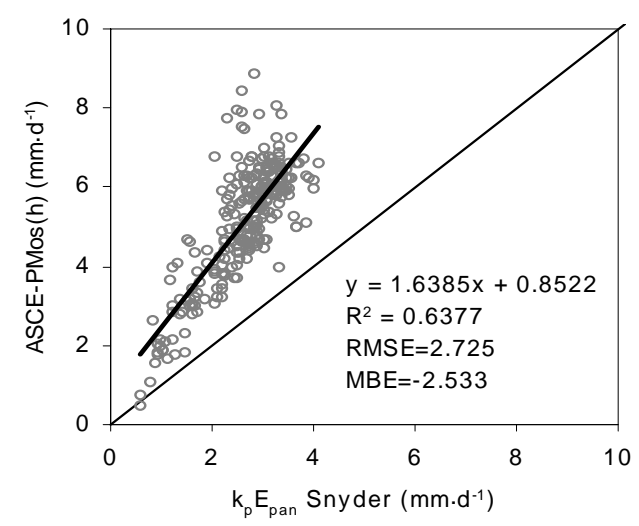

(c)

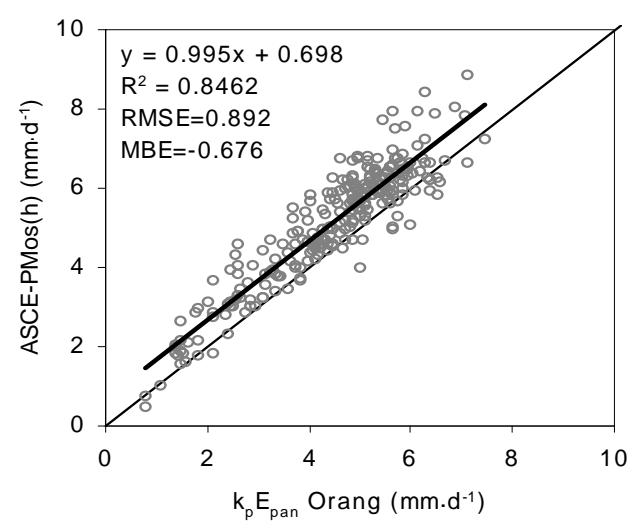

(e)

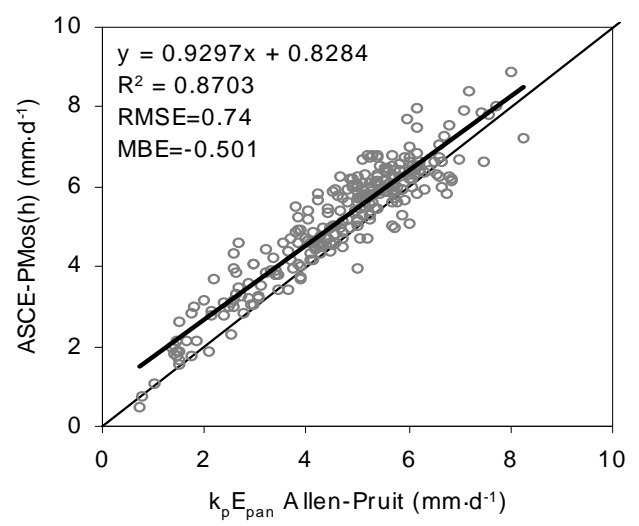

(b)

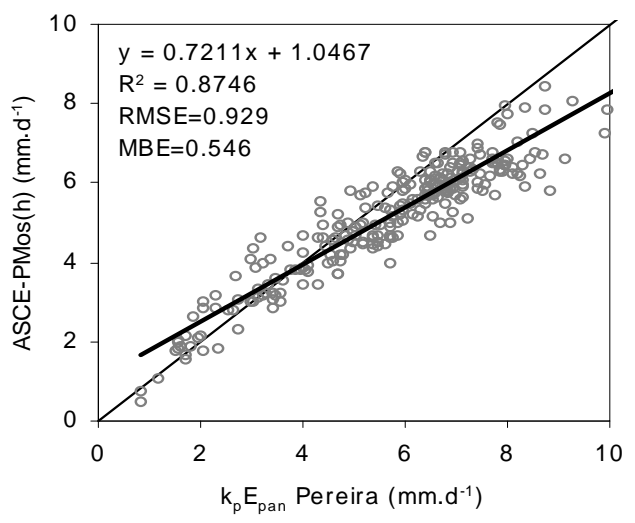

(d)

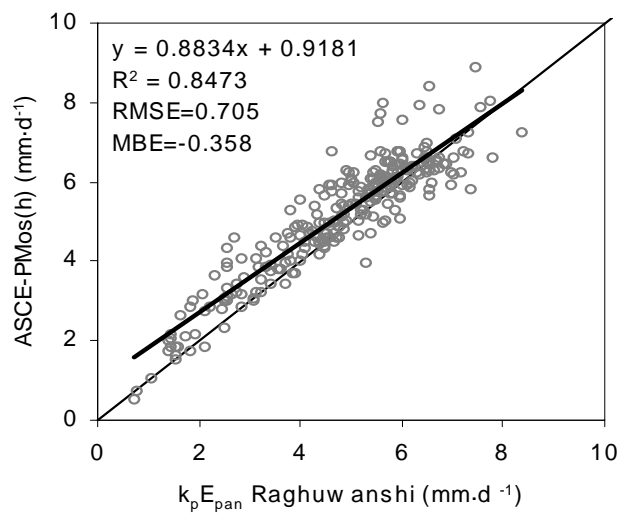

(f)

Figure 2. Comparison of the daily $E T_{o}$ estimated by ASCE-PMos(h) method and by Eq.3 using the different $k_{p}$ equations (a) Cuenca; (b) Allen \& Pruitt; (c) Snyder; (d) Pereira et al.; (e) Orang and (f) Raghuwanshi \& Wallender.

$[14,15]$, different predictive accuracy is observed among the aforementioned $k_{p}$ equations, which can be ascribed a) mainly to the different reference evapotranspiration method, which is used for the comparisons and b) secondly to the different climatic-environmental conditions. This indicates the necessity to validate these equations before their use.

\section{CONCLUSIONS}

Reference crop evapotranspiration was calculated for the irrigation period and three succeeding years using the proposed by ASCE, FAO and Hargreaves methods. Meteorological data from Thessaloniki in Northern Greece were used. ASCE-standardized Penman-Monteith method considered the reference method to evaluate the per- 
formance of the other methods.

Evaluation of the FAO-56 and Hargreaves methods was based on the calculation time step (hourly or daily) and their correspondence to the ASCE-PM. From the comparison between the different $E T_{o}$ methods a relative underestimation of the calculated $E T_{o}$ was found for all the methods compared to the daily values of ASCE$\mathrm{PM}(\mathrm{h})$, calculated in hourly time step, for both cases of the reference crop. Considering the simplicity of the Hargreaves model, it was found a very good correspondence with the ASCE-PMos(h), but it deflects for the days where the wind speed override the values of 1.5 $2.0 \mathrm{~m} \cdot \mathrm{s}^{-1}$.

$E T_{o}$ was also calculated using measurements of pan evaporation and six equations for pan coefficient $\left(k_{p}\right)$ estimation. These values evaluated in relation of ASCEPM method. The comparison analysis between the different $k_{p}$ equations resulted the following order in prediction accuracy: Cuenca > Raghuwanshi \& Wallender $>$ Allen \& Pruit $>$ Pereira et al. $>$ Orang $>$ Snyder. The Cuenca's equation indicated the best adaptation to the ASCE-PM method compared to the other equations and adequate performance for the estimation of $E T_{o}$ under the climatological-environmental conditions of the study area.

\section{REFERENCES}

[1] Doorenbos, J. and Pruitt, W.O. (1977) Guidelines for predicting crop water requirements. Irrigation and Drainage Paper No. 24, (1st and 2nd Edition). Food and Agriculture Organization of the United Nations, Rome, 179 and $156 \mathrm{pp}$.

[2] Priestley, C.H.B. and Taylor R.J. (1972) On the assessment of surface heat flux and evaporation using largescale parameters. Monthly Weather Review, 100, 81-92. doi:10.1175/1520-0493(1972)100<0081:OTAOSH $>2.3$.C O;2

[3] Allen, R.G. and Pruitt, W.O. (1991) FAO-24 reference evapotranspiration factors. Journal of Irrigation and Drainage Engineering, 117, 758-773. doi:10.1061/(ASCE)0733-9437(1991)117:5(758)

[4] Shuttleworth, W.J. and Wallace, J.S. (1985) Evaporation from sparse crops-An energy combination theory. Quarterly Journal of the Royal Meteorological Society, 111, 839-855. doi:10.1256/smsqi.46909

[5] Hargreaves, G.H. and Samani, Z.A. (1985) Reference crop evapotranspiration from temperature. Transactions of ASAE, 1, 96-99.

[6] Allen, R.G., Pereira, L.S., Raes, D. and Smith, M. (1998) Crop Evapotranspiration: Guidelines for computing crop water requirements. Irrigation and Drainage Paper No. 56, Food and Agriculture Organization of the United Nations, Rome, 300 pp.

[7] ASCE-EWRI (2005) The ASCE standardized reference evapotranspiration equation. Technical Committee Report to the Environmental and Water Resources Institute of the American Society of Civil Engineers from the Task Committee on Standardization of Reference Evapotranspiration. ASCE-EWRI, 1801 Alexander Bell Drive, Reston, VA 20191-4400, 173 Pages.

[8] Papamichail, D.M. and Terzidis, G.A. (1996) Assessment of the Meteorological Parameters-Effects on the Daily Penman Reference Evapotranspiration. 2nd International Symposium on Irrigation of Horticultural Crops, Chania, Acta Horticulturae, 449, 281-288.

[9] Papamichail, D.M. and Georgiou, P.E. (1999) Comparative analysis of hourly and daily estimates of reference evapotranspiration by using FAO Penman-Monteith equation. Proceedings of the 4th National Conference of the Greek Committee for Water Resources Management, Volos, 183-189 (in Greek).

[10] Ampas, V., Baltas, E. and Papamichail, D. (2006) Comparison of different methods for the estimation of the reference crop evapotranspiration in the Florida region. WSEAS Transactions on Environment and Development, 12, 1449-1454.

[11] Anadranistakis, M., Liakatas, A., Kerkides, P., Rizos, S., Gavanosis, J. and Poulovassilis, A. (2000) Crop water requirements model tested for crops grown in Greece. Agricultural Water Management, 45, 297-316. doi:10.1016/S0378-3774(99)00106-7

[12] Alexandris, S., Kerkides, P. and Liakatas, A. (2006) Daily reference evapotranspiration estimates by the "Copais" approach. Agricultural Water Management, 82, 371-386.

[13] Valiantzas, J.D. (2006) Simplified versions for the Penman evaporation equation using routine weather data. Journal of Hydrology, 331, 690-702. doi:10.1016/j.jhydrol.2006.06.012

[14] Gundekar H.G., Khodke, U.M., Sarkar, S. and Rai, R.K. (2008) Evaluation of pan coefficient for reference crop evapotranspiration for semi-arid region. Irrigation Science, 26, 169-175. doi:10.1007/s00271-007-0083-y

[15] Rahimikhoob, A. (2009) An evaluation of common pan coefficient equations to estimate reference evapotranspiration in a subtropical climate (north of Iran). Irrigation Science, 27, 289-296. doi:10.1007/s00271-009-0145-4

[16] Cuenca, R.H. (1989) Irrigation system design: An engineering approach. Prentice Hall, Englewood Cliffs, 552.

[17] Snyder, R.L. (1992) Equation for evaporation pan to evapotranspiration conversions. Journal of Irrigation and Drainage Engineering, 118, 977-980. doi:10.1061/(ASCE)0733-9437(1992)118:6(977)

[18] Pereira, A.R., Villanova, N., Pereira, A.S. and Baebieri, V.A. (1995) A model for the class-A pan coefficient. Agricultural Water Management, 76, 75-82.

[19] Orang, M. (1998) Potential accuracy of the popular nonlinear regression equations for estimating pan coefficient values in the original and FAO-24 tables. Unpublished rep. California Department of Water Resources, Sacramento.

[20] Raghuwanshi, N.S. and Wallender, W.W. (1998) Con- 
verting from pan evaporation to evapotranspiration. Journal of Irrigation and Drainage Engineering, 118, 977980.

[21] Antonopoulos, V. and Wyseure, G. (1998). Modeling of water and nitrogen dynamics on an undisturbed soil and a restored soil after open-cast mining. Agricultural Water Management, 37, 21-40.

doi:10.1016/S0378-3774(98)00040-7

\section{APPENDIX. EQUATIONS FOR INTER-CALCULATIONS (ASCE-EWRI, 2005)}

For hourly time step calculations:

$$
\begin{gathered}
e_{s}=e^{o}(T)=0.6108 \exp \left(\frac{17.27 T_{\mathrm{h} \text { mean }}}{T_{\mathrm{h} \text { mean }}+237.3}\right) \\
e_{a}=e^{o}\left(\mathrm{~T}_{\mathrm{h} \text { mean }}\right) \frac{R H_{\mathrm{h} \text { mean }}}{100} \\
R_{n l}=\sigma f_{c d}\left(0.34-0.14 \sqrt{e_{a}}\right) T_{\mathrm{Kh} \text { mean }}^{4}
\end{gathered}
$$

For daily time step calculations:

$$
\begin{gathered}
e_{s}=\frac{e^{o}\left(T_{\text {max }}\right)+e^{o}\left(T_{\text {min }}\right)}{2} \\
e_{a}=\frac{e^{o}\left(T_{\text {max }}\right) \frac{R H_{\text {mean }}}{100}+e^{o}\left(T_{\text {min }}\right) \frac{R H_{\text {mean }}}{100}}{2}
\end{gathered}
$$

$$
R_{n l}=\sigma f_{c d}\left(0.34-0.14 \sqrt{e_{a}}\right) \frac{T_{\mathrm{K} \text { max }}^{4}+T_{\mathrm{K} \text { min }}^{4}}{2}
$$

where $R H_{\text {hmean }}$ : mean hourly relative humidity (\%), $T_{\text {hmean }}$ and $T_{\text {Khmean }}$ : mean hourly air temperature in $\left({ }^{\circ} \mathrm{C}\right)$ and in $(\mathrm{K})$, respectively, $R_{n l}$ : mean hourly or daily net longwave radiation $\left(\mathrm{MJ} \cdot \mathrm{m}^{-2} \cdot \mathrm{h}^{-1}\right.$ or $\left.\mathrm{MJ} \cdot \mathrm{m}^{-2} \cdot \mathrm{d}^{-1}\right), \sigma$ : StefanBoltzman constant, $e_{s}$ : daily or hourly saturation vapor pressure $(\mathrm{kPa}), e_{a}$ : daily or hourly mean actual vapor pressure $(\mathrm{kPa}), f_{c d}$ : factor of relative cloudiness $0.05 \leq f_{c d}$ $\leq 1.0, T_{\text {mean }}, T_{\max }, T_{\min }$ : mean, maximum and minimum daily temperature, respectively in $\left({ }^{\circ} \mathrm{C}\right), T_{\mathrm{Kmean}}, T_{\mathrm{Kmax}}$, $T_{\mathrm{Kmin}}$ : mean, maximum and minimum daily temperature, respectively in $(\mathrm{K})$, and $R H_{\text {mean }}, R H_{\text {max }}, R H_{\text {min }}$ : mean, maximum and minimum daily relative humidity $(\%)$. 